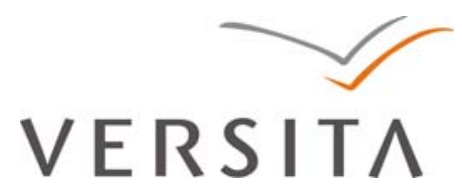

DOI: 10.2478/v10319-012-0010-2

\title{
ON COMPETENCE-BASED APPROACHES TO TEACHING ENGLISH AS A FOREIGN LANGUAGE
}

\author{
CSABA CZEGLÉDI \\ Eszterházy Károly College, Eger, \\ Matej Bel University, Banska Bystrica
}

\begin{abstract}
The paper discusses some elementary concepts and issues in competence based education (CBE) in general and in a competence-based approach to teaching English as a foreign language in particular. It is shown how some basic assumptions and concepts apparently widely adopted in CBE and language pedagogy are confusing, misguided, and incoherent and how some of the incoherence and inconsistencies may be resolved.
\end{abstract}

Key words: competence, skill, knowledge, communicative language teaching, competence-based education

\section{Introduction}

Competence-based education (CBE) has recently become the dominant international educational doctrine, which is sometimes imposed on state schools and teacher education institutions by governments in European countries, including Hungary, Britain, and Belgium, for example (cf. Lawes 2003 and Struyven and De Meyst 2010). As Struyven and De Meyst (2010) report, teacher education institutions in Belgium, for instance, are struggling to implement competence-based educational prescriptions - and they are finding it hard. One important result of the survey Struyven and De Meyst conducted shows that the majority of experienced teacher educators find that the teacher competencies prescribed in the decree issued by the Flanders Department of Education are not clear enough, therefore "insufficiently applicable” (2010:1495). This is a euphemistic way of saying that experienced instructors, curriculum designers, etc. do not understand what they are supposed to do in order to meet government prescriptions because the prescriptions are confusing. This is especially ironic in the context of CBE, as its purported goal is to enable participants to do things. If experienced teacher educators are increasingly confused about some of the key concepts of competence, as those are presented to them and 
prescribed for them in government decrees, then those decrees can hardly be said to be doing a great job of contributing to the competence of educators in their efforts to implement them.

More generally, and more importantly, educators' frustration with the conceptual content of the decrees in question and their failure to implement them in spite of the efforts they are making testify to an old simple truth, apparently overlooked by educational policy makers advocating CBE - you cannot expect anyone to act meaningfully and effectively unless they understand what they are supposed to do. The Flanders Department of Education decree, or any similar document issued by any other government, is just one example, and as such, an important symptom, of what happens, or fails to happen, when fundamental concepts that are a prerequisite for effective action remain unclear. The adopted notion of competence in CBE in general and in a competence-based approach to teaching English as a foreign language in particular, is a case in point. If CBE is based on a poor understanding of the notion of competence (and a range of related concepts including knowledge and learning), confusion is likely to occur and participants can hardly be expected to act effectively, as testified by the less than maximally successful efforts made by educators in Belgium and elsewhere and the problems they report they are having in their attempts to meet unclear prescriptions and expectations.

Competence-based education may be new to some people in teaching but certainly not for most foreign language teachers. Teaching a foreign language has always been guided, at least tacitly, by the desire to enable students to use a foreign language for an obvious function - to communicate with others in speech or in writing or both. The standard technical term that is almost universally used to denote those abilities in a student is communicative competence. It is hard to imagine that anything could go wrong either with this guiding principle or about its implementation in foreign language teaching. But education appears to be the one profession where almost anything that can be misunderstood will be misunderstood. This short essay is about how some central elements of CBE in general and competence-based English language teaching (CBELT) in particular, including the very notion of competence, have apparently been misunderstood and how some of these misunderstandings can be rectified.

\section{Some foundational concepts in CBE}

In its struggle for independence, primarily from psychology, pedagogy is noted for its tendency to borrow concepts from other disciplines, such as psychology, for example, and attempt to reinterpret them in educational theoretic terms. A well-known example is the concept of learning, which pedagogical theory has borrowed from psychology and has, remarkably unsuccessfully, been trying to redefine in its own terms (cf. Nahalka 1997). 
The concept of competence is another case in point. If indeed "competence is regarded as the possession and development of integrated skills, knowledge, appropriate attitudes and experience for the successful performance of one's life roles” (Struyven and De Meyst 2010:1496), then it is a completely incoherent and useless notion in any theory of education which adopts it. Apparently, even some of the pedagogical movements or theories that adopt it use it inconsistently. In CBE, it is sometimes used in the broad, and useless, sense just quoted and sometimes in a much narrower sense, in which it is "considered synonymous with performance skills” (ibid.). Clearly, these two different notions of competence are mutually contradictory. If a person's competence is their skill, then, quite obviously, it cannot include "skills, knowledge, appropriate attitudes and experience," whatever is meant by these terms (Struyven and De Meyst 2010:149).

How can these inconsistencies be removed and the underlying conceptual problems clarified? Let us begin with the narrower notion of competence, the simpler case. In the narrow sense, cited above, a person's competence is a skill they possess, which enables them to perform some activity, mental or physical, or a combination of the two. It is precisely in this sense that a person's mental grammar of a language is otherwise conventionally called their competence in linguistic theory (cf., Chomsky 1965, for example). What a person's linguistic competence enables them to do is to construct and understand an infinite number of different expressions in a language. If we take a person's competence to be a skill, we might just as well regard a speaker's mental grammar a special skill (cf. Ambrus and Németh 2008). Linguistic terminological tradition prefers to call a speaker's internalized grammar their competence as a matter of convention, as is the case with any other technical term in any other theory.

A person's linguistic competence is special on two counts. First, it is specifically designed for one function: to construct and interpret linguistic expressions (cf. Chomsky 1988, 2000, 2005 etc.). Second, no one is aware of their mental grammar. As nobody is aware of the rules and principles they otherwise employ in the construction and interpretation of linguistic expressions, such rules and principles, and whatever else a speaker's mental grammar contains, as well as the operation of such mental subsystems, are termed implicit. Our mental grammars are not the only implicit subsystem that enables us to carry out specific actions. There are several other things we do only if we possess the specific prerequisite implicit skills that enable us to perform them, such as swim or ride a bicycle, for example. People do such things only when they know how to. But nobody is aware of their knowledge of how to swim or ride a bicycle, or speak a language. Therefore, no cyclist, swimmer or language speaker can report anything at all about the fundamental elements of their knowledge of how to ride a bike, swim, or speak a language. These kinds of a person's procedural knowledge are implicit. 
Notice how the foregoing offers a straightforward definition of a skill, a central but rarely clarified notion in pedagogical theory, notoriously used in confusing senses, sometimes incoherently, as in the broad and narrow definitions of competence cited above. The discussion above suggests that a person's skill, such as their ability to ride a bicycle or construct and understand sentences, for example, is a specific form of implicit competence, a variety of a person's procedural knowledge, designed directly to enable that person to perform specific activities. In fact, this is the standard interpretation of a skill in cognitive psychology (cf. Ambrus and Németh 2008, already cited). This predicts that a person’s skills are each associated with specific functions, procedures or activities. A particular skill is a specific kind of a person's implicit procedural knowledge, in other words their competence, which enables that person to carry out a specific type of action, such as construct sentences or ride a bike, etc. Let us adopt this definition of a skill for the rest of the present discussion.

Let us turn to the broad sense of competence now. As already noted, the broad sense of competence is inconsistent with its narrow sense. Therefore, in principle, a theory may adopt either, but not both. In the broad sense, cited above, a person's competence includes their knowledge, skills, attitudes, and experience. What else is there in a person's mind? On this broad interpretation, a person's competence covers practically everything a human being may possess in their minds. The only exception seems to be emotions, not explicitly listed in the definition, although mentioning attitudes is a step in the direction of including a person's emotions too. Indeed, one could easily argue that emotions ought to be included, as they play an important part in human behavior or “performing one’s life roles,” such as teaching, for example.

One very simple reason why such a broad definition of a person's competence is completely useless is because on this reading, it becomes a synonym of 'anything a person may know or feel', which is entirely unhelpful either for practicing teachers or for a theory of education. It is entirely unhelpful, because it does not clarify or add anything at all to anyone’s informal understanding of what education is about. If the general goal of education is going to be redefined in the competence-based approach, as apparently it is, as the attempt to develop learners' competence, then, on the broad interpretation of competence, it amounts to saying that teachers and schools are supposed to develop anything and everything students may know or feel in order for them to be better able to perform their life roles. This is little more than a long way of saying “do something so students are a better able to do things.” Try and find one teacher in the world who disagrees with it or can name a single new element in such a characterization of what they are expected and always wanted to do. Better still, try and find any adult in the world, in or outside schools and education, who says they disagree with it or that they have a completely different idea of what education is all about. 
On a more serious note, let us turn some graver inadequacies in the broad understanding of competence. As we have seen above, the broader the notion, the less interesting or useful it becomes, right to the extent of being completely uninteresting or of any use at all. If it is extended to cover such aspects of a human mind as a person’s “skills, knowledge, appropriate attitudes and experience,” then it is not only uselessly broad but also incoherent.

First, notice that the list of components of a person's competence just quoted implies that knowledge and skills are just as different from each other as, for example, a person's attitudes are from their experience. The list also implies that a person's experience is, again, something very different from what we are ready to regard as part of their knowledge. Either implication runs counter to standard, almost universally embraced assumptions, some of them apparently adopted in CBE.

Take the question of knowledge and skills first. As already indicated in the discussion of the narrow sense of competence above, on the standard interpretation of a skill in cognitive psychology, it is a person's implicit procedural knowledge, alternatively called their competence (cf. Ambrus and Németh 2008). This entails that the concept of a skill is a subcategory of knowledge. Competence in this narrow, and the only useful, sense of the term, in which it denotes a person's procedural knowledge, is now commonplace in epistemology, cognitive psychology, or linguistics (cf. Allwright 1999, Pezzulo 2011, Ten Berge and Van Hezewijk 1999, Chomsky 1965, Pritchard 2006). Even elementary discussions of the topic, such as Pritchard (2006), for example, make a distinction between declarative knowledge, sometimes also called propositional knowledge, on the one hand, called so, because it conveniently takes the form of declarative sentences or statements, and procedural knowledge on the other hand, which is not easily reported in propositions, and which has a very different function in a person's mind - to enable them to carry out a specific activity.

Now take the second implication mentioned above, a considerably more complex issue, which, therefore, we shall not discuss here in any detail. This is the problem of how, if at all, a person's experience is fundamentally different either from what they know or from what they are able to do. On empiricist assumptions, which appear to dominate rational inquiry do date, but which are not at all adopted by the author of this essay, a person's experience is not only nondistinct from what they know, but, quite the contrary, experience is the only source, as well as the testing ground, of all of our knowledge of the world (cf., Popper 2005, for example). If this is assumed, the concept of experience is not only non-distinct form knowledge but they are nearcomplete synonyms.

In a recent alternative to empiricism, anything a person knows, including their declarative knowledge as well as any skill or competence they posses, is a personal construct of the mind of 
an individual. For a discussion of this view of knowledge, called (radical) constructivism, to be distinguished from what has come to be called social constructivism, in the context of educational theory, see Nahalka (1997). We cannot discuss any of the fundamental differences between these two competing theories of knowledge or their important implications for pedagogy here. Although these radical differences and their educational implications are truly fundamental, from the perspective of the issue immediately at hand, the problem of how experience and skills relate to the concept of knowledge, little turns on whether you are committed to empiricism or constructivism. In either case, both a person's experience and any skills they may have are aspects of their knowledge. Therefore, any notion of competence which implies or suggests otherwise, such as the broad sense of competence apparently adopted in popular variants of CBE, and some government decrees that prescribe them, is incoherent.

Finally, consider the ironic consequence of adopting a notion of competence on which it is a near-complete synonym of knowledge. Such a conceptual innovation backfires, rendering CBE, purportedly a radically new approach to education, completely indistinguishable from a conventional, informal or intuitive understanding of teaching, which it is meant to replace. Notice that to simply re-label a poorly understood and incoherently interpreted notion of knowledge as competence will not do. Rather than resolve or clarify any conceptual issues, such as, for example, how people make different uses of different sorts of knowledge in their attempts to adapt to and cope with the conditions in part imposed upon them by the world external to them, this brash terminological innovation adds to the confusion. To make matters worse, it allows both practicing teachers and educational theorists to draw undesirable conclusions about some central issues in education, such as its major goals, for example, which are otherwise not easily permitted by conventional, sometimes intuitive assumptions. We shall turn to some of these undesirable consequences in foreign language teaching directly.

\section{Elements of competence-based English language teaching}

As we have seen above, on the broad interpretation of competence, it amounts to relabeling knowledge as competence, which is not only pointless and incoherent, but, not surprisingly, may lead to some further serious misunderstandings. Some of these misunderstandings are directly relevant for foreign language teaching (FLT).

As noted early on, as far as FLT is concerned, there is nothing original or entirely new about a "competence-based approach" to it at all. Any form of FLT has always been motivated by the goal or desire to enable students to do something they otherwise could not - understand spoken or written discourse in a foreign language and produce such discourse for themselves, loosely called communication. A competence-based approach to FLT is just as obvious, and has 
been since long before anyone began to say anything at all about CBE a few decades ago, as in many other areas of education, sometimes called training, such as the education of construction engineers, medical education or the training of carpenters, brick layers, car mechanics, etc., or in what is conventionally and misleadingly called teacher training. Ironically, not for the first time in the history of education, confusion and misunderstandings occur and proliferate when an intuitively clear and natural idea is poorly developed, with some originally correct intuitions completely distorted, into an incoherent theory, sometimes called a "philosophy of education," which practically nobody understands, including government officials who nevertheless believe, or, perhaps, pretend they believe, that it is wise to prescribe such incoherent conceptual patchwork in decrees. Not surprisingly, some of the most experienced people in the profession have a hard time trying to work out what such prescriptions actually expect from them.

Take what is called communicative language teaching (CLT). The basic intuitive idea underlying CLT is quite clear and unproblematic unless unnecessary and brash innovations, partly from outside of FLT, interfere - you want your students to be able to make natural and meaningful use of the foreign language in what are loosely called communicative situations. The now familiar technical term used to denote a speaker's knowledge that enables them to do that is communicative competence. The term allows a concise formulation of the ultimate goal of FLT, universally accepted in CLT - to develop learners' communicative competence. Apparently, no formulation of the goal of FLT could be more consistent with the basic assumptions, and prescriptions, of CBE. It is easy for a language teacher to take encouragement from the central prescription of CBE and focus on developing their learners' communicative competence.

How will any foreign language teacher do that? The only way anyone can do that is by relying, minimally, on their understanding of what verbal communication is, what a person's competence is, and what a person's communicative competence is. Some important questions arise immediately.

Let us begin with an EFL teacher's notion of competence. Do they assign a broad or a narrow interpretation to this concept? And are they consistent in assigning one or the other? Similar questions arise about communicative competence. How broadly or narrowly is it construed in ELT? And what interpretation is assigned to the concept of communication?

The broad and apparently most popular but incoherent interpretation assigned to the concept of competence in CBE may suggest to the EFL teacher that a comparably broad interpretation is to be assigned to communicative competence, on which it will cover practically anything a learner may know or learn about what is called the English language, its speakers, their countries [sic], their cultures [sic], and the rules and principles of verbal communication in a narrow sense. From the perspective of the efficiency of teaching EFL (TEFL) this broad 
interpretation, although somewhat incoherent, is not necessarily undesirable, provided that an EFL teacher can discriminate between the subcomponents of this complex body of knowledge and the specific role each plays in speaking English. (Although, when that is sufficiently clearly understood, this broad concept will immediately be abandoned.) What is less attractive about this (incoherently) broad concept is an implication it has for CLT. Briefly, the implication is that CLT becomes virtually indistinguishable from any other more conservative or conventional approaches to TEFL, which, at least intuitively, always assumed that some or all of the tasks or goals subsumed under the broad concept of communicative competence were part of what an EFL teacher should do.

It is clear, then, that nothing very interesting or new can be derived about ELT in CLT, unless a sufficiently narrow concept of communication and communicative competence is adopted, a sufficiently clear and coherent, in other words narrow, concept of competence is assumed, a clear distinction is made between different types of competence in a speaker's mind, the specific function of each is clearly understood, and, finally, its made adequately clear how different types of a speaker's competence contribute to their ability to communicate in English. Any theory of or approach to ELT that falls short of these minimal conditions is inadequate. Therefore, if any variety of such and inadequate theory is adopted or imposed upon EFL teachers, it is guaranteed to jeopardize the efficiency of ELT, unless one or more of its shortcomings are intuitively rectified by practicing teachers.

As some, perhaps many, EFL teachers are aware, this is not only possible but an essential part of their daily educational routine. One easy way for an EFL teacher to outsmart an educational prescription they consider unproductive is to simply ignore it and do something different, which makes sense to them, even though they know it will count as a violation of what is expected or prescribed. I will mention only two of the best known examples of such educational prescriptions now, which, as most EFL teachers are aware, are almost universally considered outdated counterproductive dogmas, but which used to dominate the scene for quite a while.

One has to do with teaching grammar, the other with the use of the students' (and teacher's) first language in the classroom. For a long time, there used to be a ban on both. But I do not believe there is a single EFL teacher in the entire world that never violated at least one of these mindless restrictions. Whenever they did it at the right time, in the right way, and for the right purpose, they did the right thing.

Perhaps paradoxically at first sight, it is lucky that we have had to climb some slippery slopes on what we now know was the dark side of FLT. It is good, too, that we survived, without 
serious casualties. We can make good use of the experience by learning some important lessons from it. Learning from mistakes you have made is not at all paradoxical for people in FLT.

In conclusion, I will briefly discuss one important lesson to be learned from the awareness that we used to adopt but have since abandoned some assumptions, some of them prescriptions, some restrictions, etc., which we now know were to be rejected. Like the two examples I have just mentioned, none of them was ever explained or justified consistently in clear and coherent terms. None of them was ever derived from reasonable assumptions and none of them was ever based on solid principles. Instead, some of them, including the two examples above, were contradictory not only to elementary commonsense concepts but to some reasonable assumptions already adopted in the same conceptual framework that somehow managed to tolerate the presence of what are now known to have been incoherent dogmas. The lesson to be learned from this is very simple - inconsistencies, incoherent concepts, incomprehensible prescriptions or dogmas that stand without any serious justification have no place in an approach to or theory of education in general, or TEFL in particular, if it is to be of any use at all. There is a variant of this lesson that teacher educators ought to learn and bear in mind so they are better able to equip students of TEFL, for instance, with the knowledge and understanding that it takes to avoid being too easily "persuaded to join the mindless march behind the latest banner," as Widdowson (1984:33) put it nearly thirty years ago.

\section{References}

Allwright, D. 1999. Am I now, have I ever been, and could I ever be - a 'developer’? Novelty 6, no. 1: 4-19.

Ambrus, G. G. and D. Németh. 2008. Készségek, nyelv, implicit tanulás. [Skills, language, implicit learning] Pedagógusképzés 6 (35, 1-2): 43-54.

Chomsky, N. 2000. New Horizons in the Study of Language and Mind. Cambridge: Cambridge University Press.

Chomsky, N. 1965. Aspects of the Theory of Syntax. Cambridge, Mass.: MIT Press.

Chomsky, N. 1988. Language and Problems of Knowledge: The Managua Lectures. Cambridge, Mass.: MIT Press.

Chomsky, N. 2005. Three factors in language design. Linguistic Inquiry 36:1-22.

Lawes, S. 2003. What, when, how and why? Theory and foreign language teaching. Language Learning Journal, no. 28:22-28.

Nahalka, I. 1997. Konstruktív pedagógia - egy új paradigma a láthatáron [Constructive pedagogy-a new paradigm on the horizon] I. Iskolakultúra, no. 2:21-33.

Pezzulo, G. 2011. Grounding procedural and declarative knowledge in sensorimotor anticipation. Mind and Language 26(1):78-114.

Popper, K. 2005. The Logic of Scientific Discovery. London: Routledge.

Pritchard, D. 2006. What is This Thing Called Knowledge? London: Routledge.

Struyven, K and M. De Meyst. 2010. Competence-based teacher education: Illusion or reality? An assessment of the implementation status in Flanders from teachers' and students' points of view. Teaching and Teacher Education 26:1495-1510. 
Ten Berge, T. and R. Van Hezewijk. 1999. Procedural and declarative knowledge: An evolutionary perspective. Theory and Psychology 9(5):605-624.

Widdowson, H. E. 1984. Explorations in Applied Linguistics 2. Oxford: Oxford University Press. 